\title{
Charging and Discharging Period Analysis of Myristic Acid as Phase Change Material
}

\author{
Ajay M Nair" and P Vinod Kumar Naidu** \\ \#Department of Mechanical Engineering, Toc H Institute of Science and Technology, Ernakulam, India \\ ${ }^{\wedge}$ Department of Mechanical Engineering, Chaitanya Bharathi Institute of Technology, Hyderabad, India
}

Received 01 Nov 2017, Accepted 01 Jan 2018, Available online 08 Jan 2018, Vol.8, No.1 (Jan/Feb 2018)

\begin{abstract}
Energy is an essential requirement of development and prosperity of the nation, The major part of the energy requirement is met by fossil fuels but due to the impact of emission on environment and rapid depletion of fossil fuel reserves Many researchers are focussing in renewable sources especially solar energy as they are clean, cheap, abundantly available but due to intermittent nature and lack of proper storage system they are limited to take full advantage of these sources, PCMs thermal energy storage is found to be effective This paper focuses on the charging and discharging period analysis of Myristic acid as phase change material. In most of the medium temperature thermal energy storage systems (below $70^{\circ} \mathrm{C}$ ) paraffin wax was employed as a phase change material. But in the present study new PCM is being introduced which has better heat storage capacity than paraffin wax. To analyse the thermal behaviours of Myristic acid a simple and economical experimental setup has been designed which consists of solar parabolic concentrator, hot water bath, water pump, test section, insulation boxes, T type thermocouple, and Data acquisition system. In the experiment conducted, the water which gets heated due the solar parabolic concentrator charges the Myristic acid in the test section and once the Myristic acid gets fully charged it is taken out and kept in the insulation box. Charging and discharging period analysis were conducted and it is found that Myristic acid took only $2 \mathrm{hrs} 25 \mathrm{~min}$ for complete charging while it took 8hrs for a temperature drop of $8^{\circ} \mathrm{C}$ from an initial temperature of $65^{\circ} \mathrm{C}$. Thus Myristic acid is very promising as a PCM in a thermal energy storage system
\end{abstract}

\section{Keywords: Phase Change Materials, Chagrining, Discharging, Storage period}

\section{Introduction}

Energy is vital requirement for economic development and social transformation for all nations. World's energy production was largely depended on coal, later on crude oil. Due to the impacts of emission from such kind of conventional fossil fuels and the growing crisis in energy field created a new wave of research on alternate energy sources which can eliminate waste, reduce pollution, and broaden access to energy around the world. Though the availability of renewable energy is more, lack of proper storage system made it inaccessible to common people. Since solar energy is clean, cheap and abundant, it can replace and fulfill the energy need of the whole world if we could store it properly. It is essential to have an efficient thermal energy storage system as the availability of solar energy is intermittent. Phase change materials (PCMs) are one of the best options for thermal energy storage. Weihuan et al investigated the high temperature energy storage using encapsulated phase change materials for storing solar energy and conducted

*Corresponding author's ORCID ID: 0000-0002-5835-4608 DOI: https://doi.org/10.14741/ijcet.v8i01.10887 transient two dimensional heat transfer analysis. Antonio et al discussed the innovative idea of incorporating the phase change materilas into a parabolic solar cooker of the standard concentrated type.

The results shows that they could able to cook the three meals for a family with the cooker prototype both in summer and winter days. Ali et al did the analysis of encapsulated phase change materials by considering $20 \%$ void and buoyancy driven convection in a stainless steel capsule. The effect of thermal and volume expansions of the potential PCM sodium nitrate during charging and discharging were evaluated. Shazim et al prepared macro-encapsulated paraffin light weight aggregate for the development of normal weight aggregate concrete by the introduction of paraffin into porous light weight aggregate through vacuum impregnation. Mahjuz et al analysed the performance of paraffin wax based PCM thermal energy storage shell and tube water heating system by the exergy, energy and cost analyses. Munoz et al did studies on a thermal storage system for solar power plant consists of a thermocline tank with PCM capsules 
together with filler materials. It is based on the principle of multi-layered solid-PCM thermocline. The encapsulation is done by developing an external coating over a PCM pellet. Miqdam et al investigated the use of phase change material for extracting solar energy from the concentrated solar heater for water distillation. The solar energy sored in the paraffin wax PCM during the day time is used for the distillation purpose which increased the distillation efficiency of the system and there by the productivity increased by about $180 \%$. Kabeel et al constructed and compared the effect of introduction of PCM as storage medium in a solar still with conventional solar still for desalination. He used paraffin wax as phase change material. The experimental results showed that the daily freshwater productivity for the solar still with PCM is higher than that of the conventional solar still.

Many works had been done with paraffin wax as phase change materials though there are many other materials which could give better performance in energy storage. In the present work, charging and discharging period analysis of Myristic acid is done in a simple experimental setup.

\section{Experimental Setup}

The experimental apparatus consists of an insulated hot water bath, which is a rectangular metallic tank painted with black spray paint and at outside thermocol, aluminium foil, cardboard and black paper layers were used for better insulation. The top surface of the tank is having a lid which is made of thermo coal and aluminium foil to reduce the heat loss. A hot water pump is connected to the tank to pump the water to the copper coil of the parabolic solar collector.

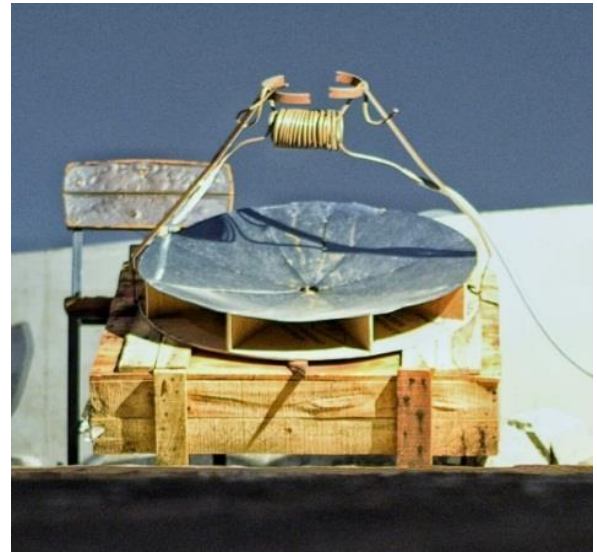

Fig1.Photograph of the experimental set up

The parabolic solar concentrator is of focal length 50 $\mathrm{cm}$, made of wooden base and the reflector portion is with aluminium sheets. Three concentric coils of $3 / 8$ inch diameter copper tube is attached just below the focal point of the parabolic solar concentrator so that entire area of the coil will be covered by the reflected sunlight copper helical coil heat exchanger. Following that a PCM cylinder made of borosilicate glass container of capacity 1 litre is used. Helical copper tube heat exchanger (of $1 / 4$ inch tube size, $8 \mathrm{~cm}$ outer diameter of coil and $10 \mathrm{~cm}$ ) is immersed in PCM (here, 500gm Myristic acid powder) kept in the borosilicate glass container. PCM container and the copper coil are kept inside an insulated tank made of card board box spray painted inside and aluminium foil pasted to thermo coal is fixed inside the box.

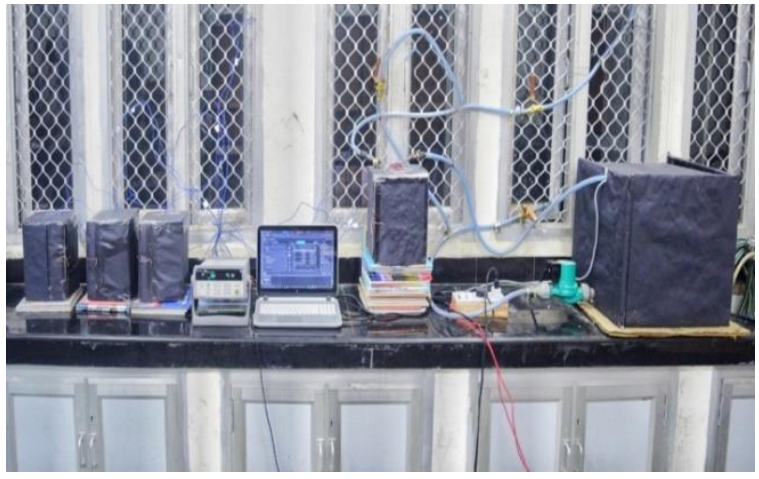

Two $\mathrm{T}$ type thermocouples are fixed at different locations inside the glass container to measure the temperatures during charging period analysis. Three other boxes are made with same material as charging period analysis box for discharging period analysis. Each of these boxes contains thermocouples. And these thermocouples are connected to a data acquisition system (Agilent 34972A LXI). The main components of the experimental setup are shown in the photograph in Figure1. Insulated charging box with copper coil heat exchanger and PCM container is shown in Figure2.

Water stored in a rectangular tank is pumped into the coil attached with solar concentrator using the hot water pump. The hot water which is coming out of the coil is made to flow through the helical copper tube heat exchanger and finally back to the hot water tank.

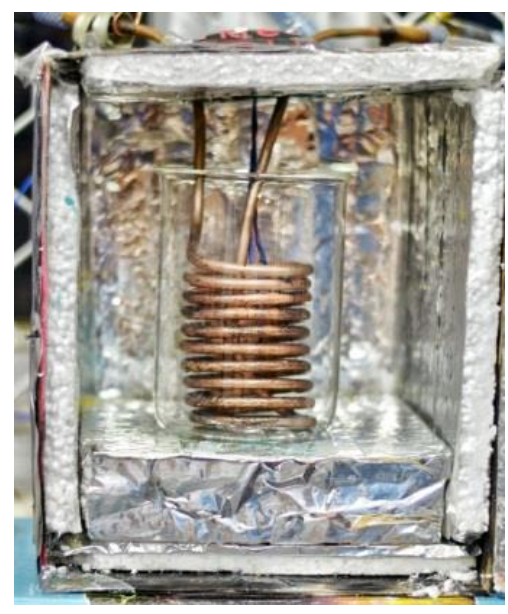

Fig 2.Insulated charging box with copper coil heat exchanger and PCM container

After the charging period analysis the glass container containing liquid PCM is kept in the other box for discharging time analysis. Properties of Myristic acid PCM is shown in Table 1. 
Table1.Properties of Myristic acid

\begin{tabular}{|c|c|c|c|c|}
\hline $\begin{array}{l}\frac{\pi}{\overparen{\pi}} \\
\frac{\pi}{\pi} \\
\sum\end{array}$ & 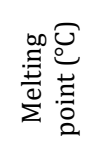 & 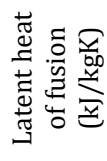 & 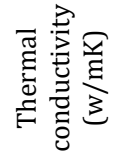 & 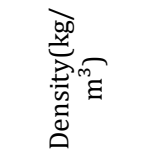 \\
\hline $\begin{array}{l}\text { Myristic } \\
\text { acid }\end{array}$ & $52-54$ & 204 & 0.17 (s) & $\begin{array}{l}861 \text { (liquid } \\
\left.55^{\circ} \mathrm{C}\right), 990( \\
\text { solid } 24^{\circ} \mathrm{C} \text { ) }\end{array}$ \\
\hline
\end{tabular}

500 gm of required PCM (Myristic acid) is taken and powdered. Sample is shown in Fig3. Then this powder is filled in the glass container and kept in the charging box for charging period analysis. After the complete melting the container with molten Myristic acid is taken out and kept inside the other tank for discharging period analysis.

\section{Results and Discussions}

During experimentation we found that pure Myristic acid is taking $2 \mathrm{hrs} 25 \mathrm{~min}$ for the complete melting. The thermocouples showed temperatures of 66.446 and $69.920{ }^{\circ} \mathrm{C}$ when the sample is completely melted. Different stages of melting of samples are shown in Fig4.1 to Fig4.3. The variation of PCM temperatures with time during charging of pure Myristic acid is shown in Figure 5.a. Storing period analysis of Myristic acid shows that pure Myristic acid had temperature drop of $8^{\circ} \mathrm{C}$ from 65.715 to $56.756^{\circ} \mathrm{C}$ in eight hours of storing. The variation of PCM temperatures with time during storing of pure Myristic acid is shown in Figure 5.b

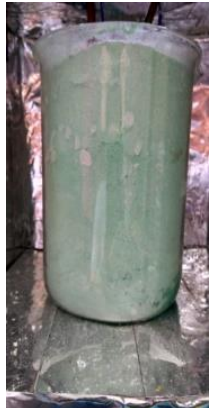

(a)

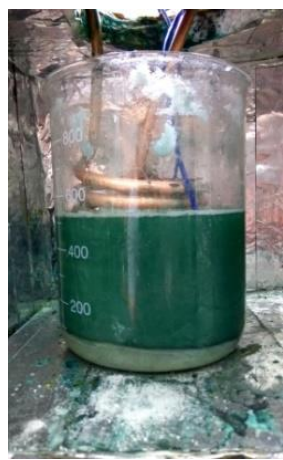

(c)

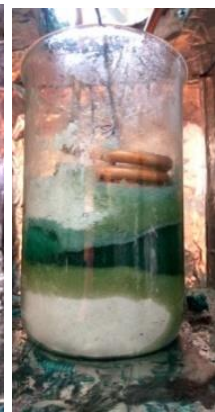

(b)
Fig4 (a)-(c) Stages during charging (a) at the beginning (b) After $1 \mathrm{hr} 20 \mathrm{~min}$ (c) After $2 \mathrm{hrs}$

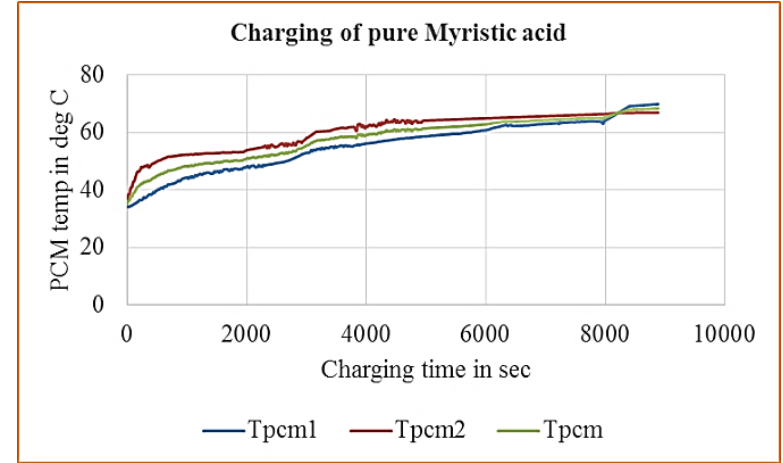

(a)

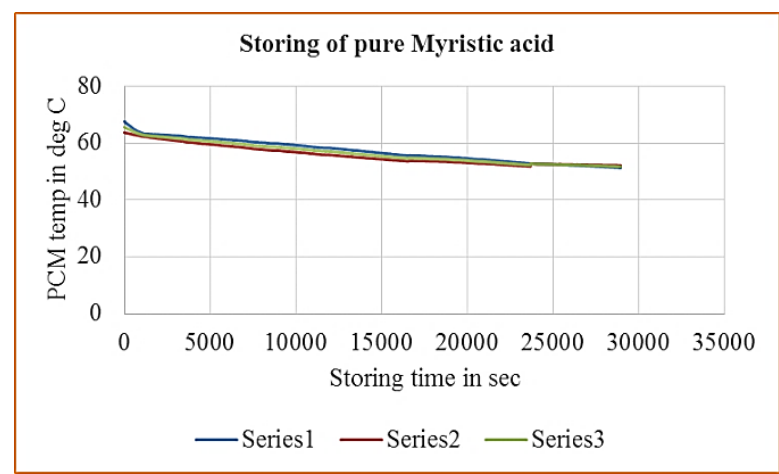

(b)

Fig 4.a Charging time vs Temp of Pure Myristic acid 4. b Storing time vs Temp of Pure Myristic acid

\section{Conclusions}

The charging and discharging period analysis of Myristic acid was done and the following conclusions are made:

1) From the charging period analysis it is clear that $500 \mathrm{gm}$ of Myristic acid took $2 \mathrm{hrs} 25 \mathrm{~min}$ for complete melting. During melting the thermocouple indicated $66^{\circ} \mathrm{C}$ inside the copper coil. It may be due to the confined heating inside the copper coil. From the graph it is evident that for a temperature rise from $45^{\circ} \mathrm{C}$ to $65^{\circ} \mathrm{C}$ it took only $2 \mathrm{hrs}$.

2) But when comes to discharging the molten Myristic acid took nearly 8 hours for a temperature drop of $8^{\circ} \mathrm{C}$ from $65^{\circ} \mathrm{C}$ to $57^{\circ} \mathrm{C}$. On further analysis it is clear that it could store heat without much temperature drop

3) The present work can be extended by using nano particle addition. By adding suitable nano particles both the charging and discharging period can be enhanced.

\section{References}

Weihuan Zhao, Ali F. Elmozughi, Alparslan Oztekin, Sudhakar Neti (2013), Heat transfer analysis of encapsulated phase change material for thermal energy storage, International Journal of Heat and Mass Transfer 63, 323-335 
Antonio Lecuona, José-Ignacio Nogueira, Rubén Ventas, María-del-Carmen Rodríguez-Hidalgo, Mathieu Legrand (2013), Solar cooker of the portable parabolic type incorporating heat storage based on PCM, Applied Energy 111, 1136-1146

Ali F. Elmozughi, Laura Solomon, Alparslan Oztekin, Sudhakar Neti (2014), Encapsulated phase change material for high temperature thermal energy storage - Heat transfer analysis, International Journal of Heat and Mass Transfer 78, 1135-1144

Shazim Ali Memona,, H.Z. Cui, Hang Zhang, Feng Xing (2015), Utilization of macro encapsulated phase change materials for the development of thermal energy storage and structural lightweight aggregate concrete , Applied Energy $139,43-55$
M.H. Mahfuz, M.R. Anisur, M.A. Kibria, R. Saidur, I.H.S.C. Metselaar (2014), Performance investigation of thermal energy storage system with Phase Change Material (PCM) for solar water heating application, International Communications in Heat and Mass Transfer 57,132-139

B. Munoz-Sancheza, I. Iparraguirre-Torresa, V. MadinaArresea, U. Izagirre-Etxeberriab, A. Unzurrunzaga-Iturbeb and A. García-Romeroc (2015), Encapsulated high temperature PCM as active filler material in a thermoclinebased thermal storage system, Energy Procedia 69, 937 946

Miqdam T. Chaichan, Hussein A. Kazem (2015), Water solar distiller productivity enhancement using concentrating solar water heater and phase change material (PCM), Case Studies in Thermal Engineering 5, 151-159

A.E. Kabeel, Mohamed Abdelgaied (2016), Improving the performance of solar still by using PCM as a thermal storage medium under Egyptian conditions, Desalination $383,22-28$ 